Check for updates

Cite this: Chem. Commun., 2018 54,11873

Received 21st August 2018,

Accepted 25th September 2018

DOI: $10.1039 / \mathrm{c} 8 \mathrm{cc} 06802 \mathrm{j}$

rsc.li/chemcomm

\section{Single-compartment hydrogen peroxide fuel cells with poly(3,4-ethylenedioxythiophene) cathodes}

\author{
Eva Miglbauer, ${ }^{\text {ab }}$ Paweł Jerzy Wójcik ${ }^{c}$ and Eric Daniel Gtowacki (D) *ad
}

\begin{abstract}
Single-compartment hydrogen peroxide fuel cells have recently emerged as a promising energy conversion platform since $\mathrm{H}_{2} \mathrm{O}_{2}$ is a high energy-density liquid that functions as both fuel and oxidizer. Finding suitable electrocatalysts is challenging since most metallic electrodes also catalyze the disproportionation reaction of $\mathrm{H}_{2} \mathrm{O}_{2}$ into $\mathrm{H}_{2} \mathrm{O}$ and $\mathrm{O}_{2}$, representing a significant loss mechanism in peroxide fuel cells. Herein we demonstrate that the conducting polymer poly(3,4-ethylenedioxythiophene), PEDOT, is a versatile electrocatalyst for peroxide fuel cells without generating losses due to disproportionation. We find that PEDOT is a cathodic catalyst for reduction of peroxide to water, performing at a level on par with the best reported inorganic catalysts. Using PEDOT as the cathode and nickel as the anode material, open circuit potentials in the range of $0.5-0.6 \mathrm{~V}$ are possible, with power densities of $0.20-0.30 \mathrm{~mW} \mathrm{~cm}$. We provide evidence to understand mechanistically how PEDOT functions as a catalyst for hydrogen peroxide reduction to water. The result of our efforts is a scalable hydrogen peroxide fuel cell cathode, which serves to demonstrate also the capabilities of organic semiconducting materials as electrocatalysts.
\end{abstract}

Fuel cells represent an important family of energy storage and conversion devices, with several mature technologies and wellestablished applications. The most prominent example is the hydrogen fuel cell, which consumes hydrogen gas as a fuel and utilizes atmospheric oxygen as an oxidizer, producing water as a byproduct. Despite its elegance, the hydrogen fuel cell has two disadvantages - the problem of storage of $\mathrm{H}_{2}$ as a gaseous fuel and the necessity of optimizing the proton-conducting separator membrane between the cathode and anode chambers to isolate the fuel from the oxidizer. ${ }^{1}$ Hydrogen peroxide fuel cells are a newer concept which retains the advantage of having a fuel cell

\footnotetext{
${ }^{a}$ Laboratory of Organic Electronics, ITN Campus Norrköping, Linköping University, Norrköping, Sweden

${ }^{b}$ Faculty of Technical Chemistry, Chemical and Process Engineering and Biotechnology, Graz University of Technology, Graz, Austria

${ }^{c}$ Redox.me AB, Norrköping, Sweden

${ }^{d}$ Wallenberg Centre for Molecular Medicine, Linköping University, Linköping,

Sweden.E-mail: eric.glowacki@liu.se
}

with water as a byproduct, but with the significant feature of aqueous hydrogen peroxide as a liquid fuel and the singlecompartment nature where $\mathrm{H}_{2} \mathrm{O}_{2}$ is both fuel and oxidizer and thus no separator is necessary. ${ }^{2-4}$ These fuel cells are part of a broader growing field of energy conversion and storage with $\mathrm{H}_{2} \mathrm{O}_{2}$, driven largely by improvements in photocatalytic platforms for conversion of solar energy into peroxide. ${ }^{5-8}$ In a hydrogen peroxide fuel cell, energy is produced because of the exergonic reactions of oxidation of hydrogen peroxide to produce oxygen and the reduction of hydrogen peroxide to water. If each of these half-reactions proceed on an anode and cathode, respectively, the energy contained in hydrogen peroxide can be electrochemically converted to electrical energy. Hydrogen peroxide reduction, at neutral to acidic $\mathrm{pH}$ values, proceeds on the cathode via eqn (1). Oxidation at the anode proceeds via eqn (2). The net reaction (eqn (3)) of producing water and oxygen from peroxide gives a net potential gain of $1.09 \mathrm{~V}$. This is close to two well-known fuel cell systems: hydrogen fuel cells have a theoretical open circuit potential of $1.23 \mathrm{~V}$ and methanol fuel cells $1.21 \mathrm{~V}$.

Cathode: $\mathrm{H}_{2} \mathrm{O}_{2}+2 \mathrm{H}^{+}+2 \mathrm{e}^{-} \rightarrow 2 \mathrm{H}_{2} \mathrm{O}(1.78 \mathrm{~V} v$ s. NHE)

$$
\begin{gathered}
\text { Anode: } \mathrm{H}_{2} \mathrm{O}_{2} \rightarrow \mathrm{O}_{2}+2 \mathrm{H}^{+}+2 \mathrm{e}^{-}(0.682 \mathrm{~V} \text { vs. NHE }) \\
\text { Total: } 2 \mathrm{H}_{2} \mathrm{O}_{2} \rightarrow 2 \mathrm{H}_{2} \mathrm{O}+\mathrm{O}_{2}(1.09 \mathrm{~V})
\end{gathered}
$$

The spontaneous decomposition of peroxide into water and oxygen has been used for outer space rocket propulsion for decades, and the possibility of using peroxide in electrochemical energy conversion schemes has been theoretically envisioned for some time. ${ }^{9,10}$ The single-compartment peroxide fuel cell concept, however, has emerged only recently. The seminal example, published by Yamazaki et al. in 2008, featured an $\mathrm{Ag}$ cathode and $\mathrm{Au}, \mathrm{Pt}$, Pd or Ni as anode in alkaline media. ${ }^{11}$ With Pt as anode the highest current was achieved but also the highest amount of decomposition of peroxide without electricity generation (disproportionation loss). With this drawback in mind, $\mathrm{Ni}$ seemed to be the best solution since it had the lowest decomposition rate and moreover it is the lowest-cost metal of the tested ones. These initial peroxide fuel cells gave low open 
circuit voltages $\left(V_{\mathrm{OC}}\right)$ of $<150 \mathrm{mV}$, with maximum current densities in the range of $1-3 \mathrm{~mA} \mathrm{~cm}^{-2}$. In subsequent years, Fukuzumi and coworkers evaluated the ability of several ironcontaining macrocyclic compounds to be suitable cathodic catalysts, though power density of such cells was limited to around $10 \mu \mathrm{W} \mathrm{cm}{ }^{-2} \cdot{ }^{12}$ Yamada et al. designed a fuel cell with an $\mathrm{Ag} / \mathrm{Ag}-\mathrm{Pb}$ alloy composite electrode as cathode and $\mathrm{Au}$ as anode in basic media. A maximum power density of $0.075 \mathrm{~mW} \mathrm{~cm}^{-2}$ at $0.065 \mathrm{~V}$ and an open circuit voltage of $150 \mathrm{mV}$ was demonstrated. ${ }^{8}$ Substantial improvement was achieved by using prussian blue on carbon paper as a cathode and $\mathrm{Ni}$ or $\mathrm{Ag}$ as anode in acidic media. A maximum power density of $1.55 \mathrm{~mW} \mathrm{~cm}^{-2}$ and an $V_{\mathrm{OC}}$ of $0.6 \mathrm{~V}$ was reached. ${ }^{13}$ The highest to-date power density of $4.2 \mathrm{~mW} \mathrm{~cm}^{-2}$ was reported by Yamada et al. They used a carbon-supported pyrazine bridged $\mathrm{Fe}\left[\mathrm{Me}(\mathrm{CN})_{4}\right]$ complex $(\mathrm{Me}=\mathrm{Pt}$ or $\mathrm{Pd})$ as cathode and $\mathrm{Ni}$ as anode. Such cells gave $V_{\mathrm{OC}}$ values between 0.7 and $0.8 \mathrm{~V} \cdot{ }^{14}$ To-date, organic semiconductors/conductors have not been explored as catalysts in hydrogen peroxide fuel cells. We have recently found that organic semiconductors are good electrocatalysts, ${ }^{15}$ photocatalysts, ${ }^{16}$ and photoelectrocatalysts ${ }^{6,17}$ for hydrogen peroxide production, encouraging us to evaluate organic electronic materials for hydrogen peroxide fuel cells. The motivation for using conducting polymers is their low-cost and ease of processability. Lacking metals, organic electronic materials can be hypothesized to not catalyze disproportionation of peroxide. Moreover, conducting polymers like polythiophenes and polyaniline are stable in various aqueous environments, and have outstanding conductivity especially in acidic conditions. Conducting polymer formulations can swell in water, forming a three-dimensional network permeable to molecules and ions. They are therefore potentially an ideal matrix to bring together electrons and reactants and function as a 3D heterogeneous electrocatalyst for peroxide fuel cells. In this paper, we have evaluated the well-known ${ }^{18}$ commercial conducting polymer poly(3,4-ethylenedioxythiophene), or PEDOT, as an active material for peroxide single-compartment fuel cells. Our peroxide fuel cells comprise a PEDOT cathode and a nickel mesh anode, the latter being chosen since this is among the most promising anodic catalysts reported to-date. ${ }^{13,14} \mathrm{~A}$ schematic illustration showing the electrochemical redox processes on the respective electrodes is shown in Fig. 1a. The hypothesis we put forth for the operation of PEDOT as a cathodic catalyst is based on the well-established doping/dedoping redox process between PEDOT ${ }^{(0)}$ and PEDOT $^{(2+)}$ (Fig. 1b). Neutral PEDOT will be oxidized by $\mathrm{H}_{2} \mathrm{O}_{2}$ to its charged bipolaronic form, which is in turn reduced back to neutral PEDOT by electrons flowing from the anode to cathode. This cycle results in the net reaction of hydrogen peroxide being reduced to water. In this study, we employed the aqueous commercial formulation of PEDOT stabilized with poly(styrene sulfonate), PSS (PH1000, Clevios $\left.^{\mathrm{TM}}\right)$. Based on previously-published methods, ${ }^{19} 20 \mathrm{~mL}$ of PH1000 was mixed with $2 \mathrm{~V} \%$ dimethylsulfoxide and $0.5 \mathrm{~V} \%$ (3-glycidyloxypropyl)trimethoxysilane, and afterwards ultrasonicated for 10 minutes. Then the mixture was poured into a Petri dish $(\varnothing 8.5 \mathrm{~cm})$ and stored under the fume hood overnight. Afterwards it was dried at $80{ }^{\circ} \mathrm{C}$ in the oven for 2 hours. a

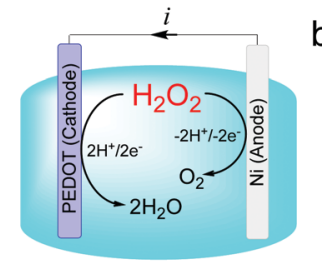

C

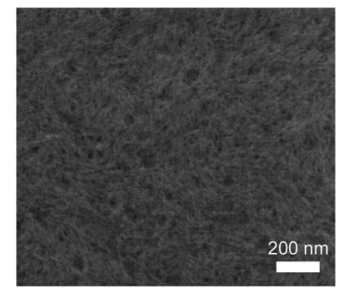

b
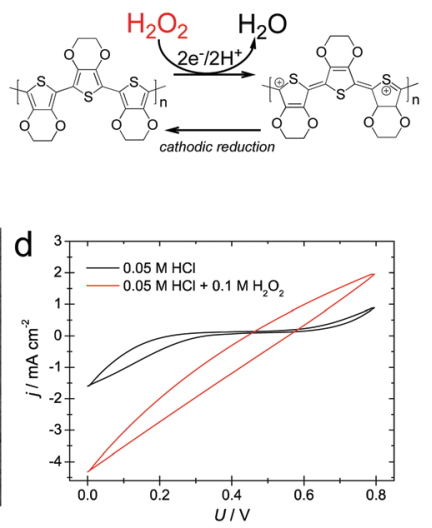

Fig. 1 (a) Schematic of the single-compartment hydrogen peroxide fuel cell. PEDOT foils function as the cathodic catalyst for peroxide reduction to water, while nickel mesh is used as the anodic catalyst throughout this work. (b) The chemical structure of PEDOT and schematic of the proposed redox cycle responsible for its action as a cathodic catalyst for $\mathrm{H}_{2} \mathrm{O}_{2}$ reduction. The neutral form of the polymer is oxidized by hydrogen peroxide, restoring the stable $\mathrm{p}$-doped state, which is then cathodically reduced to start the cycle again. The net result is the reduction of peroxide to water. (c) SEM micrograph of a PEDOT:PSS foil. The material forms a uniform mesh with a fine nanostructure of PEDOT crystallites. (d) Currentvoltage scan $\left(50 \mathrm{mV} \mathrm{s}^{-1}\right)$ of a PEDOT electrode versus nickel mesh in $0.05 \mathrm{M} \mathrm{HCl}$. Addition of $0.1 \mathrm{M} \mathrm{H}_{2} \mathrm{O}_{2}$ gives clear fuel cell behavior.

The obtained foil was removed from the dish with a tweezer. The foil was cut with scissors into suitable pieces for electrodes, usually $2 \times 5 \mathrm{~cm}$. The foils consist of a dense nanofibrous network of PEDOT crystallites (Fig. 1c), which swells and expands in water. To test if PEDOT would be a suitable cathodic catalyst for a peroxide fuel cell, we measured the current-voltage characteristics of PEDOT (cathode) versus nickel (anode), in $0.05 \mathrm{M} \mathrm{HCl}$ with and without added peroxide (two-electrode device scheme as shown in Fig. 1a). This $\mathrm{pH}$ value was chosen since it is acidic enough to be favorable for proton coupled peroxide redox reactions but where nickel is still stable. ${ }^{14}$ In the absence of peroxide, the PEDOT/Ni electrode pair yielded an $i-v$ characteristic with a small cathodic component attributed to oxygen reduction and an anodic peak characteristic of PEDOT oxidation (Fig. 1d). Addition of peroxide resulted in an obvious fuel cell effect, with a substantial increase in cathodic current and open circuit potential around $0.5 \mathrm{~V}$. This indicates that indeed PEDOT performs as a cathodic catalyst for peroxide reduction to water.

To measure in detail the fuel cell performance, we conducted step chronopotentiometry scans (Fig. 2). Different current densities were maintained for 1 minute and the final potential registered. In addition to PEDOT:PSS, we tested a PEDOT:PSS composite with Prussian blue (PB) nano/microcrystals, synthesized according to the literature. ${ }^{20} \mathrm{~PB}$ is a well-known catalyst for reduction of peroxide to water, and is one of the to-date best materials as cathodes for peroxide fuel cells. PEDOT:PSS cathodes (Fig. 2a) afforded a $V_{\mathrm{OC}}$ of $0.56 \mathrm{~V}$ and $J_{\mathrm{SC}}$ of $2.0 \mathrm{~mA} \mathrm{~cm}{ }^{-2}$, and maximum power density of $0.31 \mathrm{~mW} \mathrm{~cm}{ }^{-2}$. The addition of $\mathrm{PB}$ increases the $V_{\mathrm{OC}}$ to $0.64 \mathrm{~V}$, very close to the previously reported 

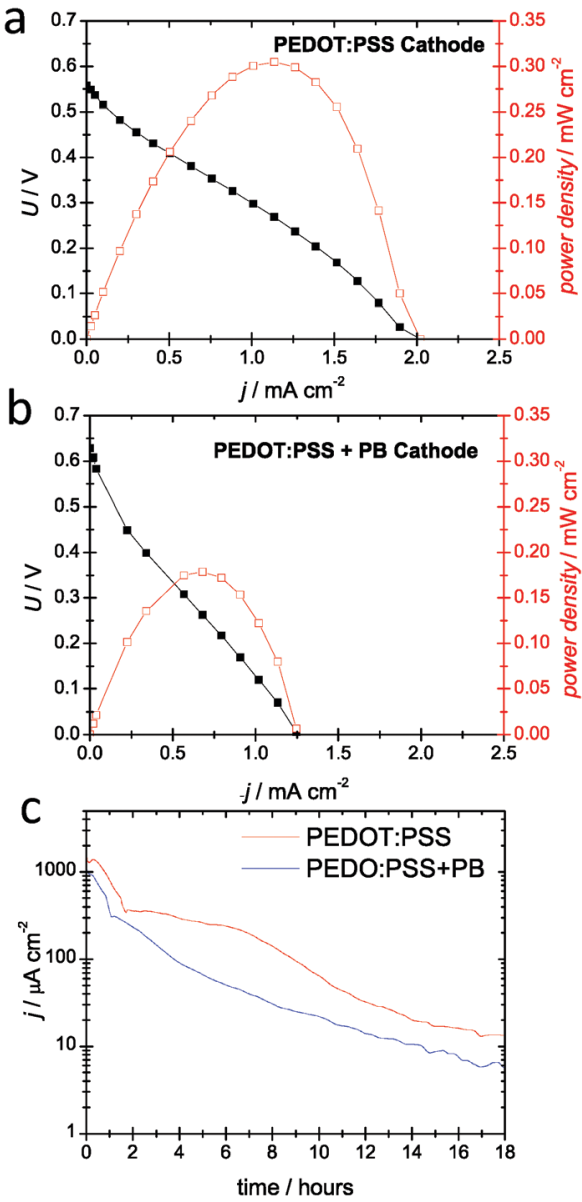

Fig. 2 Peroxide fuel cell step-scan chronopotentiometry (CP) measurements, starting conditions $0.05 \mathrm{M} \mathrm{HCl}$ and $0.1 \mathrm{M} \mathrm{H}_{2} \mathrm{O}_{2} ; \mathrm{Ni}$ mesh anode. Current was measured for 1 minute for each step. (a) CP measurement of a PEDOT:PSS cathode, (b) PEDOT:PSS + PB, (c) chronoamperometry at $0 \mathrm{~V}$ comparing the short circuit current over time for the respective cathodes.

value for PB on carbon in a peroxide fuel cell with a nickel anode (Fig. 2b). Current density does not improve however, remaining at $1.25 \mathrm{~mA} \mathrm{~cm}{ }^{-2}$. Taken together, these data show that PEDOT:PSS is an efficient catalyst in its own right, as it gives an open circuit potential very close to that of $\mathrm{PB}$. Step chronopotentiometry experiments were repeated for three cycles (each cycle $=$ 12 minutes), and demonstrated constant power density for both types of samples. We conducted a chronoamperometric measurement of holding the cell at short circuit with a starting concentration of $0.1 \mathrm{M} \mathrm{H}_{2} \mathrm{O}_{2}$. Both types of PEDOT cathodes were found to discharge at similar rates, declining to about a tenth of the starting current density after 5 hours (Fig. 2c). Having established that PEDOT is a suitable cathodic catalyst for single-compartment peroxide fuel cells, we tested if it induces the nonelectrochemical disproportionation of $\mathrm{H}_{2} \mathrm{O}_{2}$ into water and oxygen. This is a major loss mechanism in peroxide fuel cells and an obstacle for deploying many metallic catalysts. Peroxide decomposition was quantified by measuring aliquots from test solution using the horseradish peroxidase/ tetramethyl benzidine assay. ${ }^{6,21}$ We found that a $0.1 \mathrm{M} \mathrm{H}_{2} \mathrm{O}_{2}$ in $0.05 \mathrm{M} \mathrm{HCl}$ decomposes at a rate of $0.52 \mathrm{mM} \mathrm{h}^{-1}$.
Nickel accelerated peroxide decomposition to $2.6 \mathrm{mM} \mathrm{h}^{-1}$. The presence of PEDOT formulations was found not only to not induce decomposition, but to actually stabilize the peroxide solution. PEDOT:PSS slowed decomposition to $0.34 \mathrm{mM} \mathrm{h}^{-1}$.

In order to shed light on the mechanisms at play with PEDOT interacting with $\mathrm{H}_{2} \mathrm{O}_{2}$ in the context of familiar processes like oxygen-induced doping and oxygen reduction on PEDOT, we performed a series cyclic voltammetry experiments with and without $\mathrm{H}_{2} \mathrm{O}_{2}$ present (Fig. 3). In ambient conditions in $0.05 \mathrm{M} \mathrm{HCl}$ electrolyte, in the range of -0.4 to $0.8 \mathrm{~V}$ versus $\mathrm{Ag} / \mathrm{AgCl}$, PEDOT electrodes do not show any electrochemical activity save a relatively large capacitive current, characteristic of PEDOT:PSS. ${ }^{22}$ Purging with Ar prior to the experiment removes oxygen, which is known to contribute to p-doping of the PEDOT. This results is the appearance of quasi-reversible redox peaks between $0.2-0.4 \mathrm{~V}$, attributable to the oxidation and re-reduction of PEDOT $^{(0)}$. This indicates that argon purging produces some quantity of neutral PEDOT by removing oxygen. Oxygen-purging of the electrolyte eliminates these redox peaks, and produces a smaller set of faradaic peaks resulting from the oxygen reduction reaction and accompanying reoxidation of oxygen reduction products. The oxygen reduction reaction on PEDOT was recently described, as was the effect of oxygeninduced doping increasing significantly the conductivity of PEDOT. ${ }^{23}$ The addition of $\mathrm{H}_{2} \mathrm{O}_{2}$ to a concentration of $0.1 \mathrm{M}$ results in a drastic change of the cyclic voltammograms. Ambient PEDOT electrodes demonstrate a cathodic current with an onset around $0.4 \mathrm{~V}$ versus $\mathrm{Ag} / \mathrm{AgCl}$, signaling the reduction of $\mathrm{H}_{2} \mathrm{O}_{2}$ to water. Oxygen purging results in a threefold increase in this cathodic current, which can be attributed to the effect of oxygen increasing the conductivity of PEDOT. ${ }^{23}$ Purging with Ar, however, results in a five-fold increase in the $\mathrm{H}_{2} \mathrm{O}_{2}$ reduction current relative to ambient conditions. This final result, taken together with the Ar-dedoping effect described above and shown in Fig. 3a, provides strong evidence that neutral PEDOT is the key species enabling the peroxide reduction reaction. These findings support the hypothesized reaction cycle proposed in Fig. 1b. Conducting polymers have a rich redox behavior and are stable in aqueous conditions, making them interesting 3D networks where electrons, ions, and reactants can meet. This approach led us to try using the archetypical conducting polymer PEDOT to see if it can participate in the redox cycle necessary to reduce hydrogen peroxide
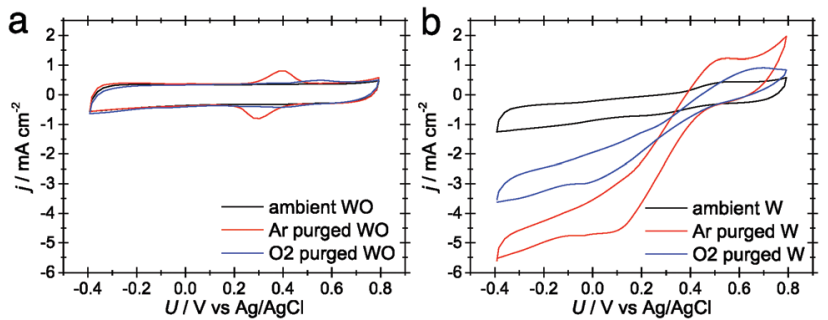

Fig. 3 Cyclic voltammograms $\left(5 \mathrm{mV} \mathrm{s}^{-1}\right)$ of PEDOT:PSS - GOPS under Ar purged, ambient and oxygen purged conditions: (a) $0.05 \mathrm{M} \mathrm{HCl}$ without peroxide (WO); (b) $0.05 \mathrm{M} \mathrm{HCl}$ with $0.1 \mathrm{M}$ peroxide (W). 
to water, critical to make cathodes for hydrogen peroxide fuel cells. These fuel cells are an interesting alternative technology to established hydrogen fuel cells, and their further development hinges on improving the performance of both cathodic and anodic catalysts. PEDOT fulfills its role as a cathodic catalyst on a level competitive with some of the best inorganic catalysts, with the benefit of not promoting peroxide disproportionation. Performance must be improved by optimizing PEDOT formulations, or by turning to other, next-generation conducting polymers. Tuning conducting polymers to become anodic catalysts for peroxide oxidation would lead to a complete "plastic" single-compartment hydrogen peroxide fuel cell. Once performance is optimized, long-term stability of conducting polymer electrodes must be carefully verified. The known stability of conducting polymer formulations in oxidizing, acidic environments speaks to them being a superior choice over metallic alternatives. Our demonstration serves as a promising first step in this direction.

This work was supported by Vinnova in the framework of Treesearch.se and by the Knut and Alice Wallenberg Foundation. E. M. is grateful for support from the Erasmus+ scholarship program of the European Commission and useful discussions with G. Trimmel at TU Graz.

\section{Conflicts of interest}

There are no conflicts to declare.

\section{Notes and references}

1 S. Srinivasan, Fuel Cells From Fundamentals to Applications, Springer, New York, 2006.

2 S. Fukuzumi, Biochim. Biophys. Acta, Bioenerg., 2016, 1857, 604-611. 3 S. Fukuzumi and Y. Yamada, ChemElectroChem, 2016, 3, 1978-1989. 4 S. Fukuzumi, Joule, 2017, 1, 689-738.
5 K. Mase, M. Yoneda, Y. Yamada and S. Fukuzumi, Nat. Commun., 2016, 7, 11470.

6 M. Jakešová, D. H. Apaydin, M. Sytnyk, K. Oppelt, W. Heiss, N. S. Sariciftci and E. D. Głowacki, Adv. Funct. Mater., 2016, 26, 5248-5254.

7 Y. Sun, I. Sinev, W. Ju, A. Bergmann, S. Dresp, S. Kühl, C. Spöri, H. Schmies, H. Wang, D. Bernsmeier, B. Paul, R. Schmack, R. Kraehnert, B. Roldan Cuenya and P. Strasser, ACS Catal., 2018, 8, 2844-2856.

8 Y. Yamada, Y. Fukunishi, S. Yamazaki and S. Fukuzumi, Chem. Commun., 2010, 46, 7334-7336.

9 R. S. Disselkamp, Energy Fuels, 2008, 22, 2771-2774.

10 R. S. Disselkamp, Int. J. Hydrogen Energy, 2010, 35, 1049-1053.

11 S. Yamazaki, Z. Siroma, H. Senoh, T. Ioroi, N. Fujiwara and K. Yasuda, J. Power Sources, 2008, 178, 20-25.

12 S. Fukuzumi, Y. Yamada and K. D. Karlin, Electrochim. Acta, 2012, 82, 493-511.

13 S. A. Mousavi Shaegh, N.-T. Nguyen, S. M. Mousavi Ehteshami and S. H. Chan, Energy Environ. Sci., 2012, 5, 8225-8228.

14 Y. Yamada, M. Yoneda and S. Fukuzumi, Inorg. Chem., 2014, 53, 1272-1274.

15 M. Warczak, M. Gryszel, M. Jakešová, V. Đerek and E. D. Głowacki, Chem. Commun., 2018, 54, 1960-1963.

16 M. Gryszel, M. Sytnyk, M. Jakesova, G. Romanazzi, R. Gabrielsson, W. Heiss and E. D. Głowacki, ACS Appl. Mater. Interfaces, 2018, 10, 13253-13257.

17 M. K. Węcławski, M. Jakešová, M. Charyton, N. Demitri, B. Koszarna, K. Oppelt, S. Sariciftci, D. T. Gryko and E. D. Głowacki, J. Mater. Chem. A, 2017, 5, 20780-20788.

18 A. Elschner, S. Kirchmeyer, W. Lovenich, U. Merker and K. Reuter, PEDOT Principles and Applications of an Intrinsically Conductive Polymer, CRC Press, 2011.

19 P. Stadler, D. Farka, H. Coskun, E. D. Głowacki, C. Yumusak, L. M. Uiberlacker, S. Hild, L. N. Leonat, M. C. Scharber, P. Klapetek, R. Menon and N. S. Sariciftci, J. Mater. Chem. C, 2016, 4, 6982-6987.

20 M. Vázquez-González, R. M. Torrente-Rodríguez, A. Kozell, A. Cecconello, S. Campuzano, J. M. Pingarron and I. Willner, Nano Lett., 2017, 17, 4958-4963.

21 P. D. Josephy, T. Eling and R. P. Mason, J. Biol. Chem., 1982, 257, 3669-3675.

22 C. M. Proctor, J. Rivnay and G. G. Malliaras, J. Polym. Sci., Part B: Polym. Phys., 2016, 1433-1436.

23 E. Mitraka, M. J. Jafari, M. Vagin, X. Liu, M. Fahlman, T. Ederth, M. Berggren, M. P. Jonsson and X. Crispin, J. Mater. Chem. A, 2017, 5, 4404-4412. 